\title{
Method of Minimizing Size of Heat Rejection Systems for Thermoelectric Coolers to Cool Detectors in Space
}

\author{
Michael K. Choi* \\ NASA Goddard Space Flight Center, Greenbelt, MD 20771
}

\begin{abstract}
A thermal design concept of attaching the thermoelectric cooler (TEC) hot side directly to the radiator and maximizing the number of TECs to cool multiple detectors in space is presented. It minimizes the temperature drop between the TECs and radiator. An ethane constant conductance heat pipe transfers heat from the detectors to a TEC cold plate which the cold side of the TECs is attached to. This thermal design concept minimizes the size of TEC heat rejection systems. Hence it reduces the problem of accommodating the radiator within a required envelope. It also reduces the mass of the TEC heat rejection system. Thermal testing of a demonstration unit in vacuum verified the thermal performance of the thermal design concept.
\end{abstract}

\section{Nomenclature}

$\begin{array}{ll}A_{c} & =\text { ampere } \\ A_{c} & =\text { cold side contact area per TEC } \\ A_{h} & =\text { hot side contact area per TEC } \\ A_{m f} & =\text { mounting flange contact area } \\ C C H P & =\text { constant conductance heat pipe } \\ G_{c} & =\text { TEC cold side contact conductance per unit area } \\ G_{h} & =\text { TEC hot side contact conductance per unit area } \\ G_{m f} & =\text { mounting flange contact conductance per unit area } \\ n & =\text { number of TECs } \\ Q_{c} & =\text { heat conduction at TEC cold side } \\ Q_{h} & =\text { heat conduction at TEC hot side } \\ T_{c} & =\text { TEC cold side temperature } \\ T_{c c h p} & =\text { CCHP temperature } \\ T_{c f} & =\text { detector cold finger temperature } \\ T_{c p} & =\text { TEC cold plate temperature } \\ T_{h} & =\text { TEC hot side temperature } \\ T_{r} & =\text { radiator temperature } \\ V & =\text { volt }\end{array}$

\section{Introduction}

$\mathrm{R}$ emote sensing instruments in space often require cold temperatures (typically $-60^{\circ} \mathrm{C}(213 \mathrm{~K})$ or colder) and tight thermal stability for detectors. Thermoelectric coolers (TECs) are often used to cool detectors actively if the detector temperature requirement is above $-113^{\circ} \mathrm{C}(160 \mathrm{~K})$. Conventionally the cold side of TECs is attached to the detector assembly directly so that waste heat from the TEC hot side is transferred to a radiator by heat pipes or thermal straps (Fig. 1). The heat load for the TEC cold side is the sum of detector power dissipation and parasitic heat conduction and radiation from the environment to the detector assembly. Typically for a temperature difference of $60^{\circ} \mathrm{C}$ or larger between the TEC cold side and hot side, its coefficient of performance (COP) is less than 0.09. It means the electrical power input to the TECs is 11.1 times or larger than the TEC cold side heat load. The total waste heat to be rejected from the TEC hot side is the sum of the electrical power input and cold side heat load. It is a significant amount if the detector assembly has multiple detectors. For example, if the TEC cold side heat load is

\footnotetext{
${ }^{*}$ Senior Aerospace Engineer, Heat Transfer, AIAA Associate Fellow.
} 
$10 \mathrm{~W}$ and the COP is 0.09 , the waste heat that needs to be rejected from the hot side is $121 \mathrm{~W}$. If heat pipe is used to transfer such a significant amount of heat from the TECs to a radiator, there are thermal penalties at both ends of the heat pipe. The first one is the thermal contact resistance at the joint between the TEC hot side and heat pipe. The second one is the thermal contact resistance at the joint between the heat pipe and the radiator. Each thermal resistance causes a temperature drop. Generally the size of a TEC is very small. Figure 2 shows an example of a three-stage TEC. ${ }^{1}$ Its hot side is about $6.1 \mathrm{~cm}^{2}$ and cold side is about $1.1 \mathrm{~cm}^{2}$. The contact area for heat conduction at either the hot side or cold side is very limited. Small contact areas limit the contact conductance and increase the temperature drop across the thermal joints. These temperature drops increase the heat rejection system size and often lead to problems of accommodating the radiator within the required envelope and meeting the instrument mass budget.

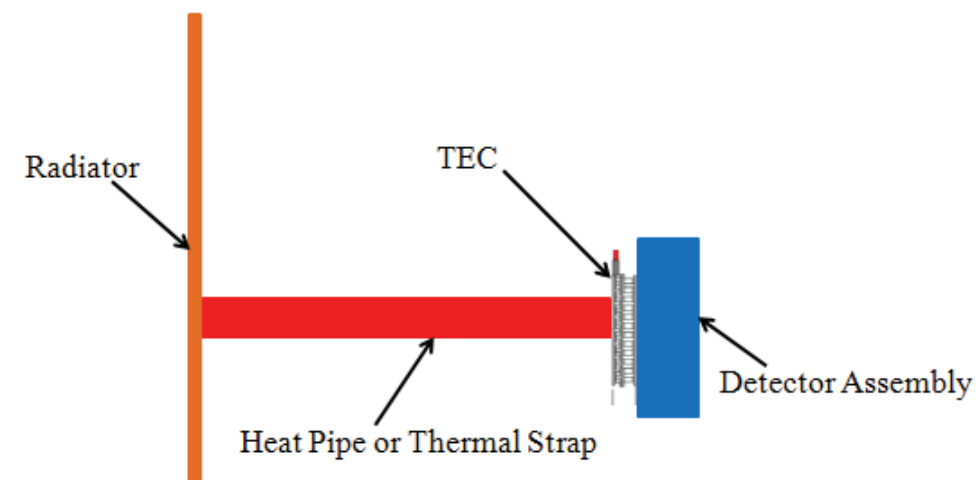

Figure 1. Conventional Heat Rejection System for TEC.
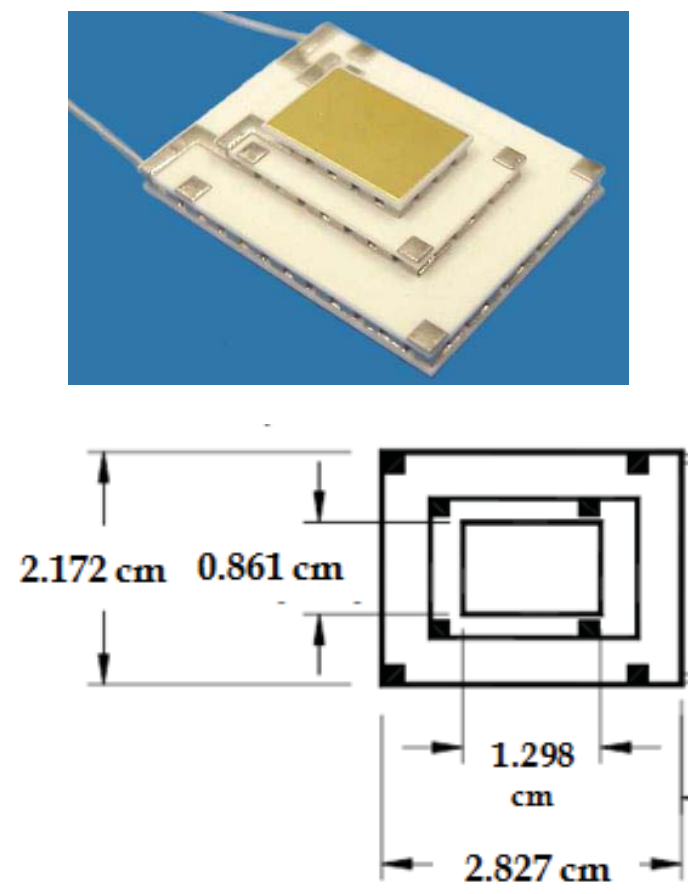

Figure 2. Typical TEC Dimensions. ${ }^{1}$ 


\section{Objective}

The objective of this paper is to present a thermal design concept of maximizing the number of TECs and attaching their hot sides to a radiator to cool detectors in space. It minimizes the size of the heat rejection system to make mechanical packaging feasible. Also it minimizes the mass of the heat rejection system.

\section{Technical Description and Novel Features of Thermal Concept}

The thermal design concept in this paper attaches the TEC hot side directly to the radiator and maximizes the number of TECs (Fig. 2). It minimizes the temperature drop between the TECs and radiator. Thus it minimizes the size of the heat rejection system. By attaching the TEC hot side to the radiator, heat is transferred directly from the TEC hot side to the radiator by conduction. It reduces the temperature drop between the TEC hot side and radiator. Also by maximizing the number of TECs, the contact area for heat conduction at both the hot side and cold side is maximized. It further reduces the temperature drops and decreases the size of the heat rejection system.

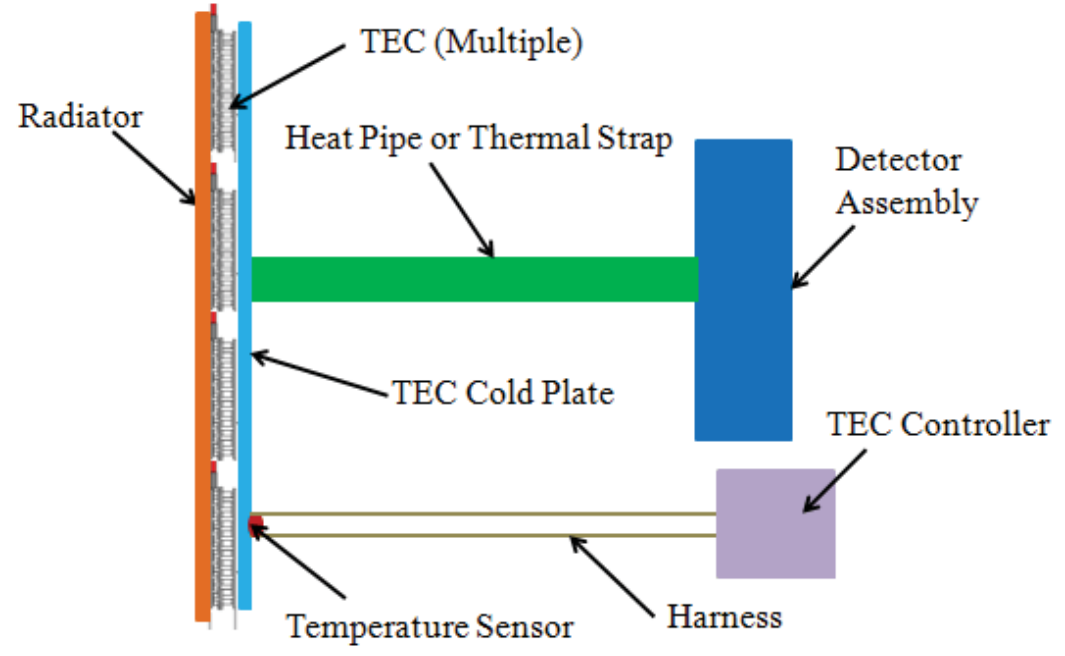

Figure 2. Concept of Minimizing Heat Rejection System for TEC.

The following equation provides the relationship between heat conduction at the TEC hot side $\left(\mathrm{Q}_{\mathrm{h}}\right)$, radiator temperature $\left(T_{r}\right)$, TEC hot side temperature $\left(T_{h}\right)$, hot side contact area per TEC $\left(A_{h}\right)$, contact conductance per unit area $\left(\mathrm{G}_{\mathrm{h}}\right)$ and the number of TECs $(\mathrm{n})$ :

$$
T_{\mathrm{r}}=\mathrm{T}_{\mathrm{h}}-\mathrm{Q}_{\mathrm{h}} /\left(\mathrm{nA}_{\mathrm{h}} \mathrm{G}_{\mathrm{h}}\right)
$$

As $\mathrm{n}$ increases, $\mathrm{T}_{\mathrm{r}}$ increases and therefore the radiator size decreases.

The following equation provides the relationship between heat conduction at the TEC cold side $\left(\mathrm{Q}_{c}\right)$, TEC cold plate temperature $\left(\mathrm{T}_{\mathrm{cp}}\right)$, TEC cold side temperature $\left(\mathrm{T}_{\mathrm{c}}\right)$, cold side contact area per TEC $\left(\mathrm{A}_{\mathrm{c}}\right)$, contact conductance per unit area $\left(\mathrm{G}_{\mathrm{c}}\right)$ and the number of TECs $(\mathrm{n})$ :

$$
\mathrm{T}_{\mathrm{cp}}=\mathrm{T}_{\mathrm{c}}-\mathrm{Q}_{\mathrm{c}} /\left(\mathrm{nA}_{\mathrm{c}} \mathrm{G}_{\mathrm{c}}\right)
$$

As $\mathrm{n}$ increases, $\mathrm{T}_{\mathrm{cp}}$ decreases and therefore the detector temperature is colder.

For the thermal design concept in this paper, the cold side of the TECs is attached to a small cold plate and a constant conductance heat pipe (CCHP) transfers heat from the detector assembly to the cold plate. The cold plate is thermally isolated from the radiator by G10 standoffs. Since the heat rejection at the cold side is at least about an order of magnitude smaller than that at the hot side, it is a significant advantage to use CCHP for transferring heat at the cold side. For detector temperatures of colder than $-70^{\circ} \mathrm{C}$, ethane CCHPs, which have flight heritage, can be used to prevent freezing. Ethane has a freezing point of $-183^{\circ} \mathrm{C}$. Since the cold side heat load is small, ethane is acceptable despite that its heat transport capacity is low. Non-condensable gas, leaks or damage by micrometeoroids could cause a heat pipe failure. Redundancy for the ethane CCHP is recommended. The ethane CCHP is insulated with multilayer insulation (MLI) blankets to minimize parasitic heat radiation from the environment. A thin layer of Kevlar is included in the MLI for micrometeoroid protection. 
As in the conventional method, "spreader" CCHPs, which are attached to the radiator backside, isothermalize the radiator. Ammonia, which has a freezing point $-77.7^{\circ} \mathrm{C}$, is adequate as a working fluid for "spreader" CCHPs.

Multiple TEC controllers are used to meet the detector thermal stability requirement by adjusting the voltage or current. Each controller controls several TECs connected in parallel circuits. Each TEC has an equal share of the cold side heat load. A temperature sensor, such as platinum resistance thermometer, attached to the TEC cold plate and adjacent to these TECs, provides temperature feedback to the controller for closed loop control.

TECs are low-cost thermal cooling devices. Presently the cost of a three-stage TEC on the market is approximately $\$ 400$. Also TECs are very light-weight. The mass of a three-stage TEC is about $20 \mathrm{~g}$. The impact of maximizing the number of TECs on the cost or mass of a heat rejection system is not significant.

\section{Case Study for Thermal Concept to Minimize Size of TEC Heat Rejection System}

A case study of using the thermal design concept to minimize the size of heat rejection system for TECs is presented. Assuming a remote sensing instrument has eight detectors, including mercury cadmium telluride $(\mathrm{HgCdTe})$ and charged coupled device $(\mathrm{CCD})$. The detectors have a $-83^{\circ} \mathrm{C}(190 \mathrm{~K})$ temperature requirement and $\pm 0.2^{\circ} \mathrm{C}$ thermal stability requirement. The total power dissipation is $1.5 \mathrm{~W}$. The detectors are thermally isolated from the instrument mechanical structure. The estimated total parasitic heat load for the detectors is $1.2 \mathrm{~W}$. After adding a $30 \%$ contingency, the total heat load to be removed from the detectors is $3.51 \mathrm{~W}$. The detectors are cooled by using 28 three-stage TECs that have the following specifications: $1.54 \mathrm{ohm}$ resistance; $8.9 \mathrm{~V}$ maximum voltage; $5.3 \mathrm{~A}$ maximum current. Four TEC controllers are used, so that each controller controls 7 TECs. The following assumptions are made for the TECs:

- Hot side temperature $\left(\mathrm{T}_{\mathrm{h}}\right):-23.5^{\circ} \mathrm{C}$

- $\quad$ Cold side temperature: $-86.5^{\circ} \mathrm{C}$

- $\quad \Delta \mathrm{T}$ between hot side and cold side: $63^{\circ} \mathrm{C}$

- Coefficient of performance (COP): 0.0875

- Total heat removal at cold side $\left(\mathrm{Q}_{\mathrm{c}}\right): 3.51 \mathrm{~W}$

- Total electrical power input: $40.1 \mathrm{~W}$

- Power input to each TEC: $1.43 \mathrm{~W}$

- Voltage: $1.484 \mathrm{~V}$

- Current: $0.964 \mathrm{~A}$

- Electronics controller with tolerance of $\pm 0.005 \mathrm{~A}$ or $\pm 0.007 \mathrm{~V}$ is required

- Heat rejection at hot side $\left(\mathrm{Q}_{\mathrm{h}}\right): 43.61 \mathrm{~W}$

- Hot side area per TEC $\left(\mathrm{A}_{\mathrm{h}}\right): 6.1 \mathrm{~cm}^{2}$

- Hot side contact conductance $\left(\mathrm{G}_{\mathrm{h}}\right): 0.25 \mathrm{~W}^{\circ} \mathrm{C}^{-1} \mathrm{~cm}^{-2}$

- Cold side area per TEC $\left(\mathrm{A}_{\mathrm{c}}\right): 1.1 \mathrm{~cm}^{2}$

- Cold side contact conductance $\left(\mathrm{G}_{\mathrm{c}}\right): 0.25 \mathrm{~W}^{\circ} \mathrm{C}^{-1} \mathrm{~cm}^{-2}$

It is assumed that the TEC hot side is attached to the radiator by using an epoxy such as Stycast 2850FT. The gap filler for the cold side thermal joints is assumed to be indium foil. The contact conductance assumed is from Wolff and Schneider ${ }^{2}$.

Substituting the appropriate numbers into Eq. (1), the radiator temperature $\left(T_{r}\right)$ is $-24.46^{\circ} \mathrm{C}$. The temperature drop between the radiator and TEC hot side is only $0.96^{\circ} \mathrm{C}$. Substituting the appropriate numbers into Eq. (2), the cold plate temperature $\left(\mathrm{T}_{\mathrm{cp}}\right)$ is $-86.04^{\circ} \mathrm{C}$. The temperature drop between the TEC cold plate and TEC cold side is only $0.46^{\circ} \mathrm{C}$.

Assuming a $25.4 \mathrm{~cm}$ long ethane CCHP is used to transfer heat from a detector cold finger to the TEC cold plate, a mounting flange at each end of the CCHP. Despite that ethane has low heat transport capacity, it is acceptable since the cold side heat load is only $3.51 \mathrm{~W}$.

The following equations provide the relationship between heat conduction at each CCHP mounting flange $\left(\mathrm{Q}_{\mathrm{c}}\right)$, TEC cold plate temperature $\left(T_{\text {cp }}\right)$, CCHP temperature $\left(T_{\text {cchp }}\right)$, detector cold finger temperature $\left(T_{\text {cf }}\right)$, mounting flange contact area $\left(A_{m f}\right)$, and contact conductance per unit area $\left(\mathrm{G}_{\mathrm{mf}}\right)$ :

$$
\begin{aligned}
& \mathrm{T}_{\mathrm{cchp}}=\mathrm{T}_{\mathrm{cp}}-\mathrm{Q}_{\mathrm{c}} /\left(\mathrm{A}_{\mathrm{mf}} \mathrm{G}_{\mathrm{mf}}\right) \\
& \mathrm{T}_{\mathrm{cf}}=\mathrm{T}_{\text {cchp }}-\mathrm{Q}_{\mathrm{c}} /\left(\mathrm{A}_{\mathrm{mf}} \mathrm{G}_{\mathrm{mf}}\right)
\end{aligned}
$$

The following assumptions are made for the CCHP: 
- Mounting flange area $\left(\mathrm{A}_{\mathrm{mf}}\right): 13 \mathrm{~cm}^{2}$

- Mounting flange contact conductance $\left(\mathrm{G}_{\mathrm{mf}}\right): 0.25 \mathrm{~W}^{\circ} \mathrm{C}^{-1} \mathrm{~cm}^{-2}$

- $\Delta \mathrm{T}$ between mounting flanges: $0^{\circ} \mathrm{C}$

Substituting the appropriate numbers into Eq. (3), the CCHP temperature $\left(\mathrm{T}_{\text {cchp }}\right)$ is $-84.96^{\circ} \mathrm{C}$. The temperature drop between the CCHP and mounting flange is only $1.08^{\circ} \mathrm{C}$. Substituting the appropriate numbers into Eq. (4), the detector cold finger temperature $\left(\mathrm{T}_{\mathrm{cf}}\right)$ is $-83.88^{\circ} \mathrm{C}$, which is $0.88^{\circ} \mathrm{C}$ colder than the detector temperature requirement. The temperature drop between the detector cold finger and mounting flange is also only $1.08^{\circ} \mathrm{C}$.

\section{Verification of Minimizing TEC Heat Rejection System Size by Thermal Testing}

A demonstration unit of the thermal design concept to minimize the size of heat rejection system for TECs was built and tested in vacuum at Goddard Space Flight Center in 2013. It is depicted in Fig. 3. Figure 4 and Fig. 5 display the integrated thermal hardware of the demonstration unit and AZ93 white paint radiator respectively. The demonstration unit thermal verification test setup in the vacuum chamber is shown in Fig. 6. The test assembly was tilted so that the ethane CCHP was in the reflux mode to overcome the problem of gravity.

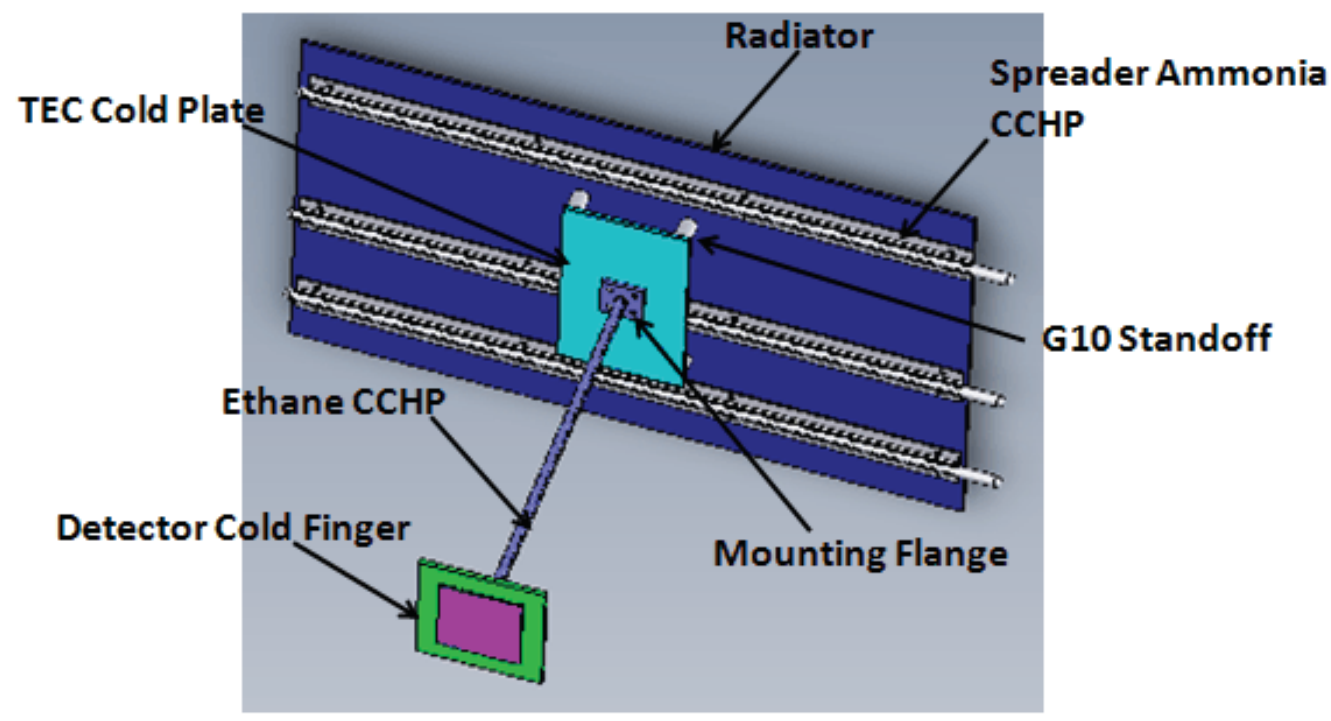

Figure 3. TEC Heat Rejection System Demonstration Unit.

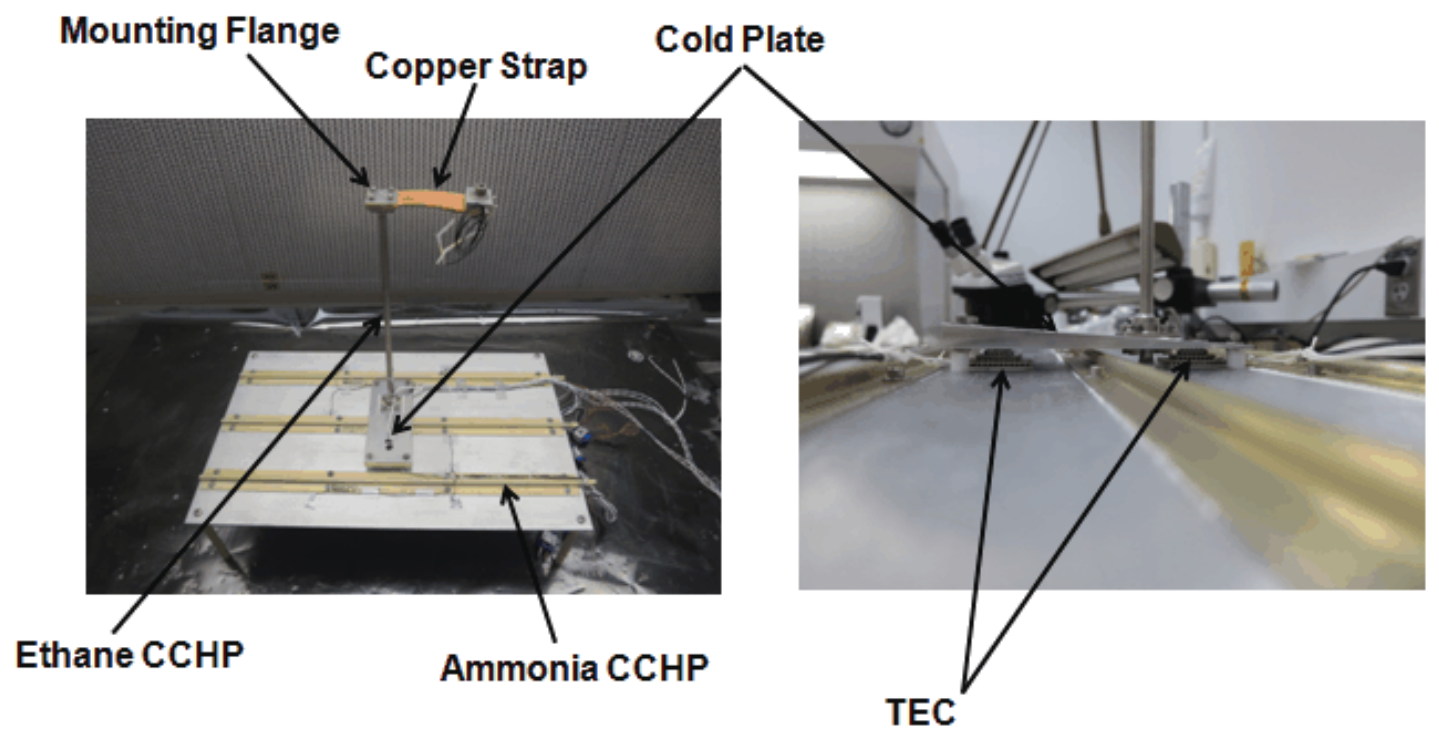

Figure 4. TEC Heat Rejection System Demonstration Unit Integrated Hardware. 


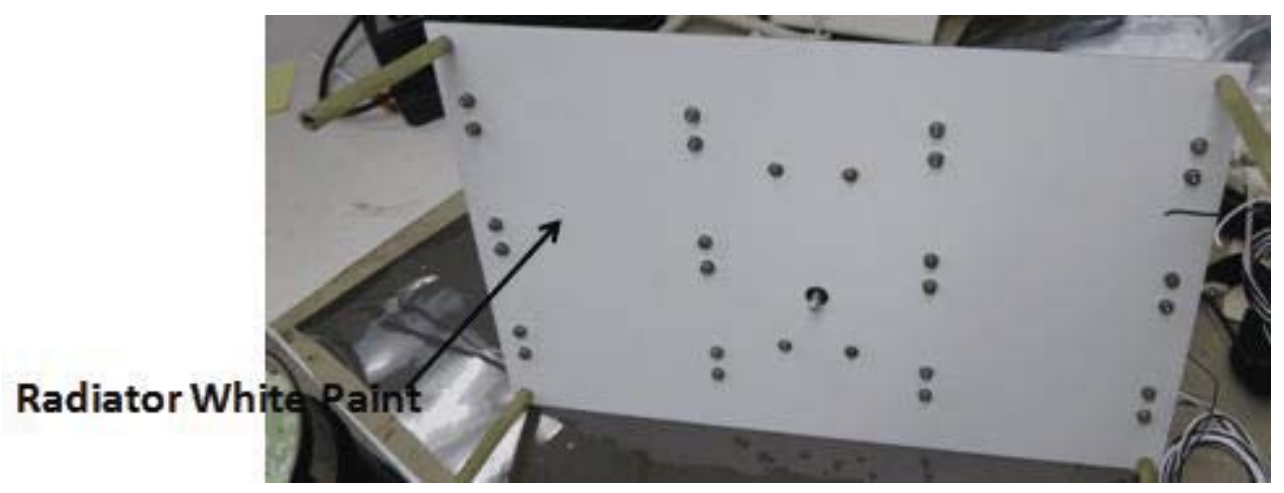

Figure 5. TEC Heat Rejection System Demonstration Unit Radiator with White Paint.

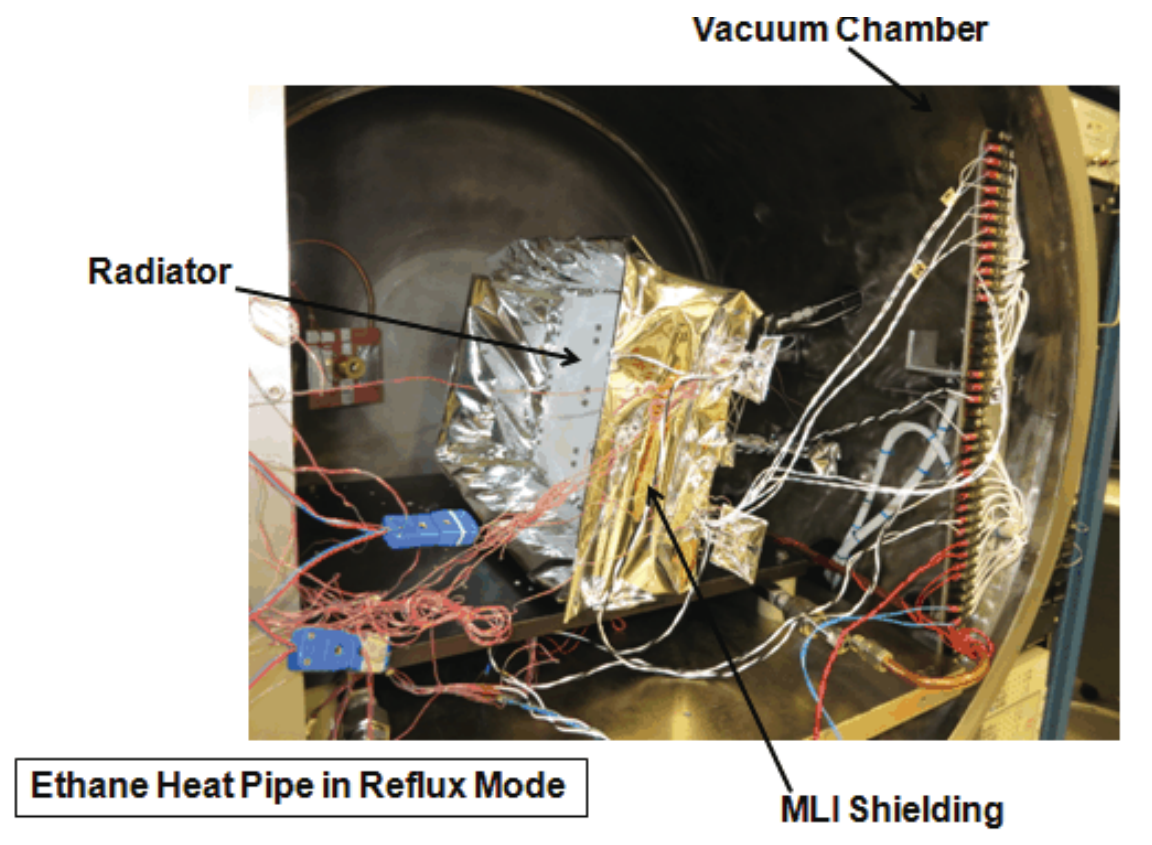

Figure 6. TEC Heat Rejection System Demonstration Unit in Vacuum Chamber.

Table 1 presents the temperature data recorded in the demonstration unit thermal verification test. The temperature of the TEC cold plate was $-87.1^{\circ} \mathrm{C}$, which was $62.1^{\circ} \mathrm{C}$ colder than the radiator. The temperature of the ethane CCHP mounting flange to copper strap interface was $-84.5^{\circ} \mathrm{C}$. The temperature gradient between the TEC cold plate and ethane CCHP mounting flange to copper strap interface was $2.6^{\circ} \mathrm{C}$. The test results verified the thermal performance of the TEC heat rejection system thermal design concept.

Table 1. Temperatures Recorded in Demonstration Unit Thermal Verification Test.

\begin{tabular}{|c|c|}
\hline Component & Temperature $\left({ }^{\circ} \mathrm{C}\right)$ \\
\hline Radiator & -25.0 \\
\hline TEC Cold Plate & -87.1 \\
\hline Ethane CCHP Mounting Flange/Copper Strap Interface & -84.5 \\
\hline Copper Strap/Detector Assembly Interface & -83.3 \\
\hline
\end{tabular}




\section{Conclusion}

The thermal design concept for TEC heat rejection systems in this paper has the following advantages. It minimizes the temperature drop between the TEC hot side and radiator. It minimizes the size of such heat rejection systems. It reduces the problem of accommodating the radiator in a required envelope. Also it reduces the mass of heat rejection systems. Thermal testing of a demonstration unit in a vacuum chamber in 2013 verified the thermal performance of the thermal design concept.

\section{References}

${ }^{1} \mathrm{http}: / /$ www.marlow.com/products/thermoelectric-modules/

${ }^{2}$ Wolff, E. G. and Schneider, D. A., "Prediction of Thermal Contact Resistance between Polished Surfaces", Int'1 Journal of Heat and Mass Transfer 41 (1998), 3469-3482. 